\title{
Association between IL-1RN gene polymorphisms and susceptibility to ankylosing spondylitis: a large Human Genome Epidemiology review and meta-analysis
}

\author{
G.X. Jin, J.Z. Duan, W.L. Guo, L. Li, S.Q. Cui and H. Wang \\ Department of Orthopedics Surgery, \\ Shengjing Hospital of China Medical University, Shenyang, China \\ Corresponding author: H. Wang \\ E-mail: cmu_wh@163.com
}

Genet. Mol. Res. 12 (2): 1720-1730 (2013)

Received May 14, 2012

Accepted March 2, 2013

Published May 21, 2013

DOI http://dx.doi.org/10.4238/2013.May.21.3

\begin{abstract}
We made a Human Genome Epidemiology review and meta-analysis to examine a possible association between interleukin-1 receptor antagonist (IL-1RN) polymorphisms and susceptibility to ankylosing spondylitis (AS). Studies of IL-1RN polymorphisms and susceptibility to AS were found by searching the Pubmed, Cochrane library, Embase, Web of Science, Springerlink, CNKI, and CBM databases. Data were extracted by 2 independent reviewers. The metaanalysis was performed with the Review Manager Version 5.1.6 and STATA Version 12.0 software. The odds ratio (OR) and $95 \%$ confidence intervals $(95 \% \mathrm{CI})$ were calculated based on the extracted data. Thirteen studies with 5391 AS cases and 5239 healthy controls were retrieved. Seven IL-1RN polymorphisms were addressed, including rs30735, rs31017, rs419598, rs315951, rs315952, rs27810, and VNTR. Metaanalysis showed that the $\mathrm{rs} 30735^{*} \mathrm{C}$ allele/carrier, the rs $31017 * \mathrm{G}$ carrier and the rs $315952 * \mathrm{~T}$ carrier were positively and significantly associated with susceptibility to AS $(\mathrm{OR}=1.45,95 \% \mathrm{CI}=1.19-1.76$; $\mathrm{OR}=1.73$, $95 \% \mathrm{CI}=1.34-2.24 ; \mathrm{OR}=1.30,95 \% \mathrm{CI}=1.01-1.69 ; \mathrm{OR}=1.54,95 \% \mathrm{CI}$ $=1.16-2.04)$. A subgroup analysis based on ethnicity revealed significant positive associations between the $\operatorname{rs} 30735^{*} \mathrm{C}$ allele/carrier and the
\end{abstract}


rs $31017 *$ G allele and susceptibility to AS in both Caucasian and Asian populations, while the positive association between the rs315952*T carrier and AS susceptibility was significant only in Asian populations $(\mathrm{OR}=1.54,95 \% \mathrm{CI}=1.16-2.04)$. This meta-analysis suggests that IL-1RN polymorphisms are involved in the pathogenesis of AS. The rs $30735^{*} \mathrm{C}$ allele/carrier, and the $\mathrm{rs} 31017 * \mathrm{G}$ allele may be risk factors for ankylosing spondylitis in Caucasians and Asians, while the rs315952*T carrier is associated with susceptibility to this disease only in Asians.

Key words: Interleukin-1 receptor antagonist; Genetic polymorphisms; Ankylosing spondylitis; Susceptibility; Meta-analysis

\section{INTRODUCTION}

Ankylosing spondylitis (AS) is one of the most common chronic spondyloarthropathies and is characterized by inflammation of the spine and sacroiliac joints; it can be an outcome of any of the spondyloarthropathy subtypes (El Maghraoui, 2011). AS is a common cause of inflammatory arthritis, with a prevalence of $0.25 \%$ in European populations (Reveille et al., 2010); men are affected at half the rate of women (Feldtkeller et al., 2003). Most patients with AS develop the first symptoms at 25-45 years of age (Braun and Sieper, 2007). Although AS is the product of an interaction between environmental triggers, susceptibility genes, gender, age, and ethnicity (Zhang et al., 2011), the precise pathogenic mechanism of AS is unknown. Previous studies have confirmed HLA-B27 as the major genetic key associated with AS (16-40\%) (Peloso et al., 2011). However, HLA-B27 cannot explain all patients with AS, as only $5 \%$ of HLA-B27-positive individuals develop AS (Duan et al., 2012), indicating that there are other contributing causes.

Familial clustering has often been considered as an indication of genetic factors in disease etiology (Baraliakos et al., 2008). The interleukin-1 (IL-1) family gene cluster consists of 3 genes: IL-1A, IL-1B, and IL-1RN. IL-1A and -B encode pro-inflammatory cytokines IL-1 $\alpha$ and IL-1 $\beta$, which have been implicated in joint destruction. IL-1RN encodes IL-1 receptor antagonist (IL-1Ra), an anti-inflammatory non-signaling molecule that prevents IL-1 receptor signaling by competitive inhibition (van der Paardt et al., 2002; Maksymowych et al., 2003; Timms et al., 2004; Kim et al., 2005). Several studies have addressed the association between members of the IL-1 gene cluster and AS susceptibility (Laval et al., 2001). Most of these studies focused on the IL-1A, IL-1B, and IL-1RN genes, especially the IL-1RN variable number of tandem repeat polymorphism (VNTR). None of these studies demonstrated a connection between AS susceptibility and the IL-1 gene cluster. Recently, 2 independent studies suggested associations between VNTR $* 2$ in intron 2 and single-nucleotide polymorphisms (SNPs) in exon 6 of the IL-1RN gene (McGarry et al., 2001; Maksymowych et al., 2003) and AS susceptibility. However, some of these studies yielded conflicting results (Guo et al., 2010). Since we could not draw definitive conclusions about IL-1RN polymorphisms and AS susceptibility from these studies, we decided to perform a meta-analysis.

\section{MATERIAL AND METHODS}

\section{Literature search}

Pubmed, Cochrane library, Embase, Web of Science, Springerlink, CNKI, and CBM 
databases were searched (last search was updated on March 30, 2012) to identify relevant studies. The search terms included ["ankylosing spondylitis" or "spondylitis, ankylosing" (Mesh)] and ["polymorphism, single nucleotide" or "polymorphism, genetic" (Mesh)] and ["Interleukin-1 receptor antagonist" or "IL-1RN" (Mesh)]. References in eligible studies or textbooks were also reviewed.

\section{Inclusion and exclusion criteria}

The included studies had to meet the following criteria: the type of study had to be a case-control study; the study must have focused on associations between IL-1RN polymorphisms and AS susceptibility; the diagnosis principle of AS had to strictly match with the modified New York criteria (1984); the frequencies of alleles or genotypes in case and control groups had to be capable of extraction; and the publication had to be in English or Chinese. Studies were excluded when they were not case-control studies of IL-RN polymorphisms and susceptibility to AS if they were based on incomplete data or if useless or overlapping data were reported.

\section{Data extraction}

Using a standardized form, data from published studies were extracted independently by 2 reviewers (W.L. Guo and L. Li) to collect information including: first author, year of publication, country, language, ethnicity, study design, diagnostic criteria, source of cases and controls, number of cases and controls, mean age, sample, detection methods, polymorphism genotype frequency, and evidence of Hardy-Weinberg equilibrium (HWE) in controls. In cases of conflicting evaluations, an agreement was reached following a discussion with a third reviewer ( $\mathrm{H}$. Wang).

\section{Quality assessment of included studies}

Two reviewers (G.X. Jin and J.Z. Duan) independently assessed the quality of the papers according to modified STROBE quality score systems (Vandenbroucke et al., 2007; Zhang et al., 2011). Forty quality appraisal items were used in this meta-analysis, with scores ranging from 0 to 40 . Scores of $0-20,20-30$, and 30-40 were defined as low, moderate, and high quality, respectively. Disagreement was resolved by discussion.

\section{Statistical analysis}

Allele or genotype frequencies of IL-1RN SNPs were determined by the allele counting method. The odds ratio (OR) and $95 \%$ confidence intervals $(95 \% \mathrm{CI})$ were calculated with Review Manager Version 5.1.6 (provided by the Cochrane Collaboration, available at: http:// ims.cochrane.org/revman/download) and STATA Version 12.0 (Stata Corp, College Station, TX, USA). Between-study variations and heterogeneities were estimated using the Cochran Q-statistic (Zintzaras and Ioannidis, 2005; Peters et al., 2006); P $\leq 0.05$ was considered to represent statistically significant heterogeneity. We also quantified the effect of heterogeneity by using a recently developed method called $\mathrm{I}^{2}$, which ranges from 0 to $100 \%$ and represents the proportion of inter-study variability that can be attributed to heterogeneity rather than chance. Whenever a significant $\mathrm{Q}$-test $(\mathrm{P} \leq 0.05)$ or $\mathrm{I}^{2}>50 \%$ indicated heterogeneity, a random-effect model was generated for meta-analysis. Otherwise, the fixed-effect model was used. To establish the effect of heterogeneity on meta-analysis conclusions, subgroup analysis was performed. The $\chi^{2}$ test was used to determine whether the control genotype frequencies were in HWE. Fun- 
nel plots have often been used to detect publication bias. However, due to limitations of varied sample size and subjective reviews, the Egger linear regression test (Higgins and Thompson, 2002), which measures funnel plot asymmetry using a natural logarithm scale of OR, was used to evaluate publication bias. Publication bias was considered to be significant at $\mathrm{P}<0.1$.

\section{RESULTS}

\section{The characteristics of included studies}

According to the inclusion criteria, 13 studies (McGarry et al., 2001; van der Paardt et al., 2002; Maksymowych et al., 2003; Timms et al., 2004; Kim et al., 2005; Chou et al., 2006; Lin et al., 2006; Maksymowych et al., 2006; Yang et al., 2007; Agrawal et al., 2008; Liu et al., 2008; Sims et al., 2008; Guo et al., 2010) were included and 53 were excluded. A flow chart of the study selection process is shown in Figure 1. The total number of AS cases and healthy controls were 5391 and 5239 in the 13 case-control studies that evaluated the relationship between IL-1RN polymorphisms and AS susceptibility. Publication year ranged from 2001 to 2010. All patients fulfilled the 1984 modified New York criteria for diagnosis of AS. Seven IL-1RN polymorphisms were addressed, including rs30735, rs31017, rs419598, rs315951, rs315952, rs27810, and VNTR. The most common polymorphisms were VNTR, rs315952, rs31017, and rs30735. The HWE test was conducted for the controls in every study. Four studies of mainly Asian populations were not in $\operatorname{HWE}(\mathrm{P}<0.05)$ (McGarry et al., 2001; Lin et al., 2006; Agrawal et al., 2008; Liu et al., 2008); all others were in HWE (P > 0.05). All quality scores were $>20$ (moderately to high quality). The characteristics and methodological quality of the studies included are summarized in Table 1.

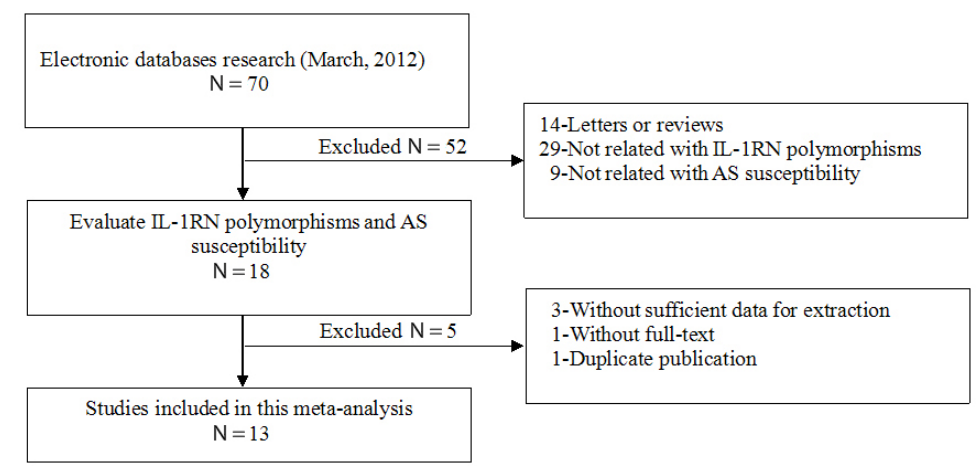

Figure 1. Flow chart shows study selection procedure. Thirteen case-control studies were included in this meta-analysis.

\section{Association between IL-1RN polymorphisms and AS risk}

A summary of the meta-analysis findings of the association between IL-1RN polymorphisms and AS susceptibility is provided in Table 2 . The meta-analysis showed that the rs $30735^{*} \mathrm{C}$ allele/carrier, the rs $31017^{*} \mathrm{G}$ carrier and the $\mathrm{rs} 315952^{*} \mathrm{~T}$ carrier had positive associations with $\mathrm{AS}$ susceptibility $(\mathrm{OR}=1.45,95 \% \mathrm{CI}=1.19-1.76, \mathrm{P}=0.0002 ; \mathrm{OR}=1.73,95 \% \mathrm{CI}=1.34-2.24, \mathrm{P}<$ $0.0001 ; \mathrm{OR}=1.30,95 \% \mathrm{CI}=1.01-1.69, \mathrm{P}=0.04 ; \mathrm{OR}=1.54,95 \% \mathrm{CI}=1.16-2.04, \mathrm{P}=0.003$, respectively). However, there were no significant associations for $\mathrm{rs} 27810^{*} \mathrm{C}$ allele/carrier, rs $31017^{*} \mathrm{G}$ 


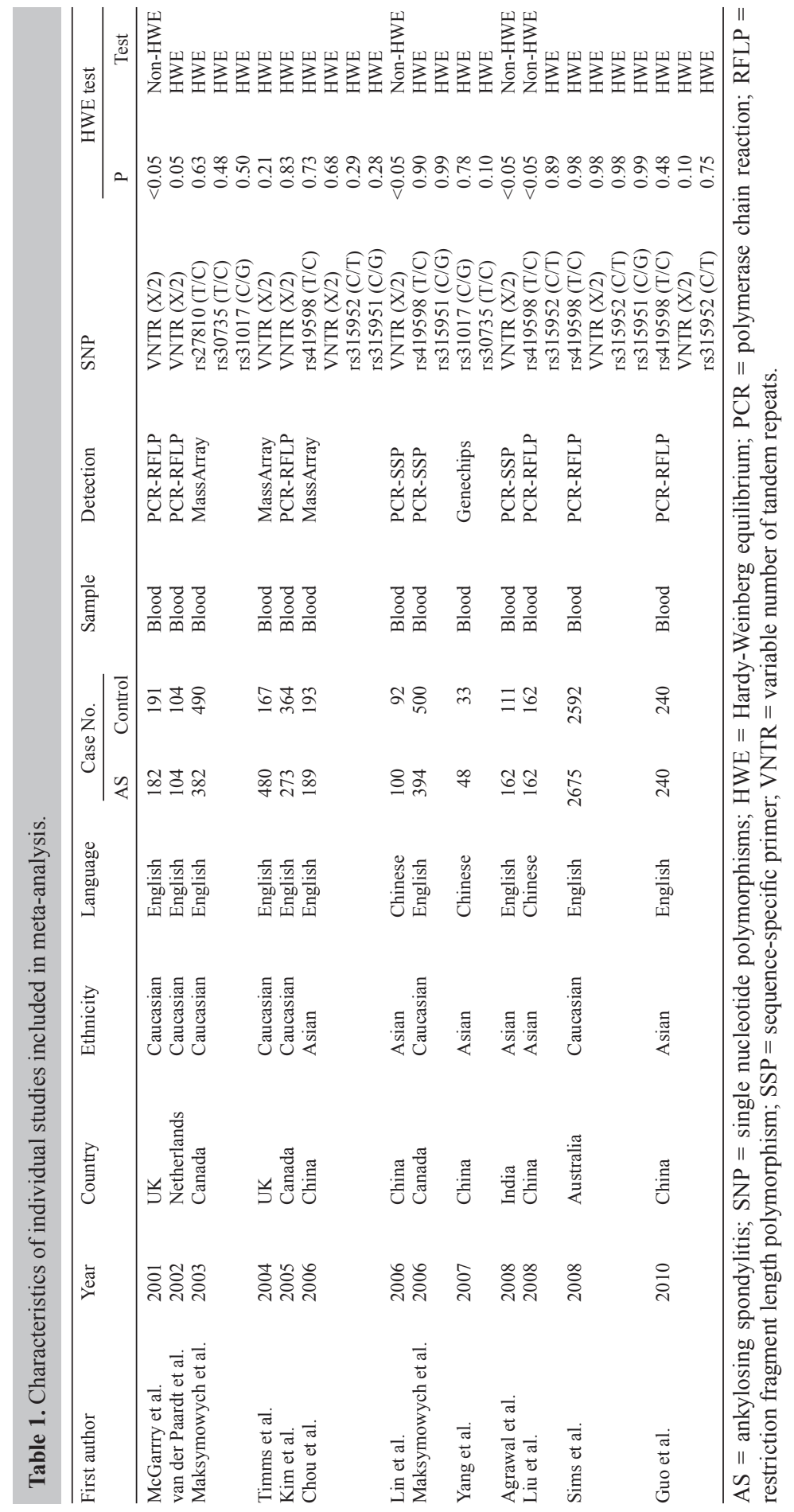


allele, rs315951*G allele/carrier, rs315952*T allele, rs419598*C allele/carrier, and VNTR*2 allele/carrier (all $\mathrm{P}>0.05$ ). In the subgroup analysis based on ethnicity, subjects were divided into Caucasian and Asian populations. There were positive associations between the rs $30735^{*} \mathrm{C}$ allele/ carrier, and the rs $31017 * \mathrm{G}$ allele and AS susceptibility in Caucasian populations $(\mathrm{OR}=1.40$, $95 \% \mathrm{CI}=1.14-1.71, \mathrm{P}=0.001 ; \mathrm{OR}=1.66,95 \% \mathrm{CI}=1.27-2.18, \mathrm{P}=0.0002 ; \mathrm{OR}=1.24,95 \% \mathrm{CI}=$ $1.01-1.53, \mathrm{P}=0.04$, respectively). Similarly, the $\mathrm{rs} 30735^{*} \mathrm{C}$ allele/carrier and the $\mathrm{rs} 31017^{*} \mathrm{G}$ allele were significantly associated with $\mathrm{AS}$ susceptibility in Asian populations $(\mathrm{OR}=2.27,95 \% \mathrm{CI}=$ $1.05-4.91, \mathrm{P}=0.04 ; \mathrm{OR}=2.74,95 \% \mathrm{CI}=1.11-6.77, \mathrm{P}=0.03 ; \mathrm{OR}=2.67,95 \% \mathrm{CI}=1.40-5.10, \mathrm{P}$ $=0.003$, respectively). In addition, a positive association was found between the rs $315952 * \mathrm{~T}$ carrier and AS susceptibility only in Asian populations $(\mathrm{OR}=1.54,95 \% \mathrm{CI}=1.16-2.04, \mathrm{P}=0.003)$. Nevertheless, rs $27810 * \mathrm{C}$ allele/carrier, rs $315951 * \mathrm{G}$ allele/carrier, rs315952*T allele, rs $419598 * \mathrm{C}$ allele/carrier, and VNTR*2 allele/carrier also showed no association with AS susceptibility in Caucasian and Asian populations (all $\mathrm{P}>0.05$ ). Sensitivity analysis was performed by sequential omission of non-HWE studies. The significance of pooled OR in all individual analyses and subgroup analyses was not influenced excessively by omitting any single study. The positive associations between IL-1RN polymorphisms and AS susceptibility are shown in Figure 2.

\begin{tabular}{|c|c|c|c|c|c|c|c|}
\hline Polymorphisms & Eligible studies & AS cases & Controls & OR $(95 \% \mathrm{CI})$ & $P$ & Heterogeneity test & Effect model \\
\hline Rs27810*C allele & 1 & $225 / 764$ & $312 / 980$ & $0.89(0.73-1.10)$ & 0.28 & - & Fixed \\
\hline Caucasian & 1 & $225 / 764$ & $312 / 980$ & $0.89(0.73-1.10)$ & 0.28 & - & \\
\hline Rs $27810^{*} \mathrm{C}$ carrier & 1 & $203 / 382$ & $260 / 490$ & $1.00(0.77-1.31)$ & 0.98 & - & Fixed \\
\hline Caucasian & 1 & $203 / 382$ & $260 / 490$ & $1.00(0.77-1.31)$ & 0.98 & - & \\
\hline Rs $30735^{*} \mathrm{C}$ allele & 2 & $304 / 876$ & $285 / 1048$ & $1.45(1.19-1.76)$ & 0.0002 & $\mathrm{P}=0.24, \mathrm{I}^{2}=29 \%$ & Fixed \\
\hline Caucasian & 1 & $272 / 776$ & $274 / 984$ & $1.40(1.14-1.71)$ & 0.001 & - & \\
\hline Asian & 1 & $32 / 100$ & $11 / 64$ & $2.27(1.05-4.91)$ & 0.04 & - & \\
\hline Rs $30735^{*} \mathrm{C}$ carrier & 2 & $269 / 438$ & $252 / 525$ & $1.73(1.34-2.24)$ & $<0.0001$ & $\mathrm{P}=0.30, \mathrm{I}^{2}=6 \%$ & Fixed \\
\hline Caucasian & 1 & $237 / 388$ & $239 / 492$ & $1.66(1.27-2.18)$ & 0.0002 & - & \\
\hline Asian & 1 & $32 / 50$ & $13 / 33$ & $2.74(1.11-6.77)$ & 0.03 & - & \\
\hline Rs $31017^{*} \mathrm{G}$ allele & 2 & $310 / 862$ & $300 / 1042$ & $1.71(0.82-3.58)$ & 0.15 & $\mathrm{P}=0.03, \mathrm{I}^{2}=79 \%$ & Random \\
\hline Caucasian & 1 & $252 / 766$ & $276 / 976$ & $1.24(1.01-1.53)$ & 0.04 & - & \\
\hline Asian & 1 & $58 / 96$ & $24 / 66$ & $2.67(1.40-5.10)$ & 0.003 & - & \\
\hline Rs $31017^{*} \mathrm{G}$ carrier & 2 & $247 / 431$ & $260 / 521$ & $1.30(1.01-1.69)$ & 0.04 & $\mathrm{P}=0.28, \mathrm{I}^{2}=15 \%$ & Fixed \\
\hline Caucasian & 1 & $210 / 383$ & $240 / 488$ & $1.25(0.96-1.64)$ & 0.10 & - & \\
\hline Asian & 1 & $37 / 48$ & $20 / 33$ & $2.19(0.83-5.77)$ & 0.11 & - & \\
\hline Rs $315951 * \mathrm{G}$ allele & 3 & $1858 / 3362$ & $1955 / 3470$ & $0.93(0.79-1.10)$ & 0.38 & $\mathrm{P}=0.12, \mathrm{I}^{2}=54 \%$ & Random \\
\hline Caucasian & 2 & $1716 / 2982$ & $1784 / 3078$ & $0.99(0.86-1.14)$ & 0.86 & $\mathrm{P}=0.22, \mathrm{I}^{2}=34 \%$ & \\
\hline Asian & 1 & $142 / 380$ & $171 / 392$ & $0.77(0.58-1.03)$ & 0.08 & - & \\
\hline Rs315951*G carrier & 1 & $117 / 190$ & $130 / 196$ & $0.81(0.54-1.23)$ & 0.33 & - & Fixed \\
\hline Asian & 1 & $117 / 190$ & $130 / 196$ & $0.81(0.54-1.23)$ & 0.33 & - & \\
\hline Rs315952*T allele & 4 & $2599 / 4424$ & $2350 / 4140$ & $1.08(0.99-1.18)$ & 0.07 & $\mathrm{P}=0.69, \mathrm{I}^{2}=0 \%$ & Fixed \\
\hline Caucasian & 1 & $1972 / 3246$ & $1774 / 3004$ & $1.07(0.97-1.19)$ & 0.17 & - & \\
\hline Asian & 3 & $627 / 1178$ & $576 / 1136$ & $1.11(0.95-1.31)$ & 0.20 & $\mathrm{P}=0.52, \mathrm{I}^{2}=0 \%$ & \\
\hline Rs315952*T carrier & 3 & $481 / 589$ & $423 / 568$ & $1.54(1.16-2.04)$ & 0.003 & $\mathrm{P}=0.44, \mathrm{I}^{2}=0 \%$ & Fixed \\
\hline Asian & 3 & $481 / 589$ & $423 / 568$ & $1.54(1.16-2.04)$ & 0.003 & $\mathrm{P}=0.44, \mathrm{I}^{2}=0 \%$ & \\
\hline Rs419598*C allele & 5 & $1198 / 5222$ & $1137 / 5122$ & $1.03(0.77-1.38)$ & 0.83 & $\mathrm{P}=0.0006, \mathrm{I}^{2}=80 \%$ & Random \\
\hline Caucasian & 2 & $1080 / 4046$ & $1031 / 3944$ & $1.01(0.85-1.20)$ & 0.91 & $\mathrm{P}=0.13, \mathrm{I}^{2}=56 \%$ & \\
\hline Asian & 3 & $118 / 1176$ & $106 / 1178$ & $1.05(0.44-2.47)$ & 0.91 & $\mathrm{P}=0.0002, \mathrm{I}^{2}=88 \%$ & \\
\hline Rs419598*C carrier & 3 & $110 / 588$ & $95 / 589$ & $1.14(0.42-3.10)$ & 0.80 & $\mathrm{P}<0.0001, \mathrm{I}^{2}=90 \%$ & Random \\
\hline Asian & 3 & $110 / 588$ & $95 / 589$ & $1.14(0.42-3.10)$ & 0.80 & $\mathrm{P}<0.0001, \mathrm{I}^{2}=90 \%$ & \\
\hline VNTR $* 2$ allele & 9 & $1273 / 5904$ & $1115 / 5344$ & $1.10(0.85-1.41)$ & 0.46 & $\mathrm{P}<0.0001, \mathrm{I}^{2}=77 \%$ & Random \\
\hline Caucasian & 5 & $1115 / 4534$ & $987 / 4078$ & $1.08(0.83-1.40)$ & 0.58 & $\mathrm{P}=0.004, \mathrm{I}^{2}=74 \%$ & \\
\hline Asian & 4 & $158 / 1370$ & $128 / 1266$ & $1.18(0.59-2.34)$ & 0.64 & $\mathrm{P}=0.0003, \mathrm{I}^{2}=84 \%$ & \\
\hline VNTR $* 2$ carrier & 7 & $447 / 1451$ & $243 / 1095$ & $1.39(0.86-2.24)$ & 0.18 & $\mathrm{P}<0.0001, \mathrm{I}^{2}=81 \%$ & Random \\
\hline Caucasian & 3 & $309 / 766$ & $134 / 462$ & $1.50(0.89-2.51)$ & 0.12 & $\mathrm{P}=0.05, \mathrm{I}^{2}=67 \%$ & \\
\hline Asian & 4 & $138 / 685$ & $109 / 633$ & $1.33(0.55-3.21)$ & 0.53 & $\mathrm{P}<0.0001, \mathrm{I}^{2}=88 \%$ & \\
\hline
\end{tabular}

Cases and controls are reported as number of individuals/total individuals. AS $=$ ankylosing spondylitis; $\mathrm{OR}=$ odds ratios; $95 \% \mathrm{CI}=95 \%$ confidence interval. 


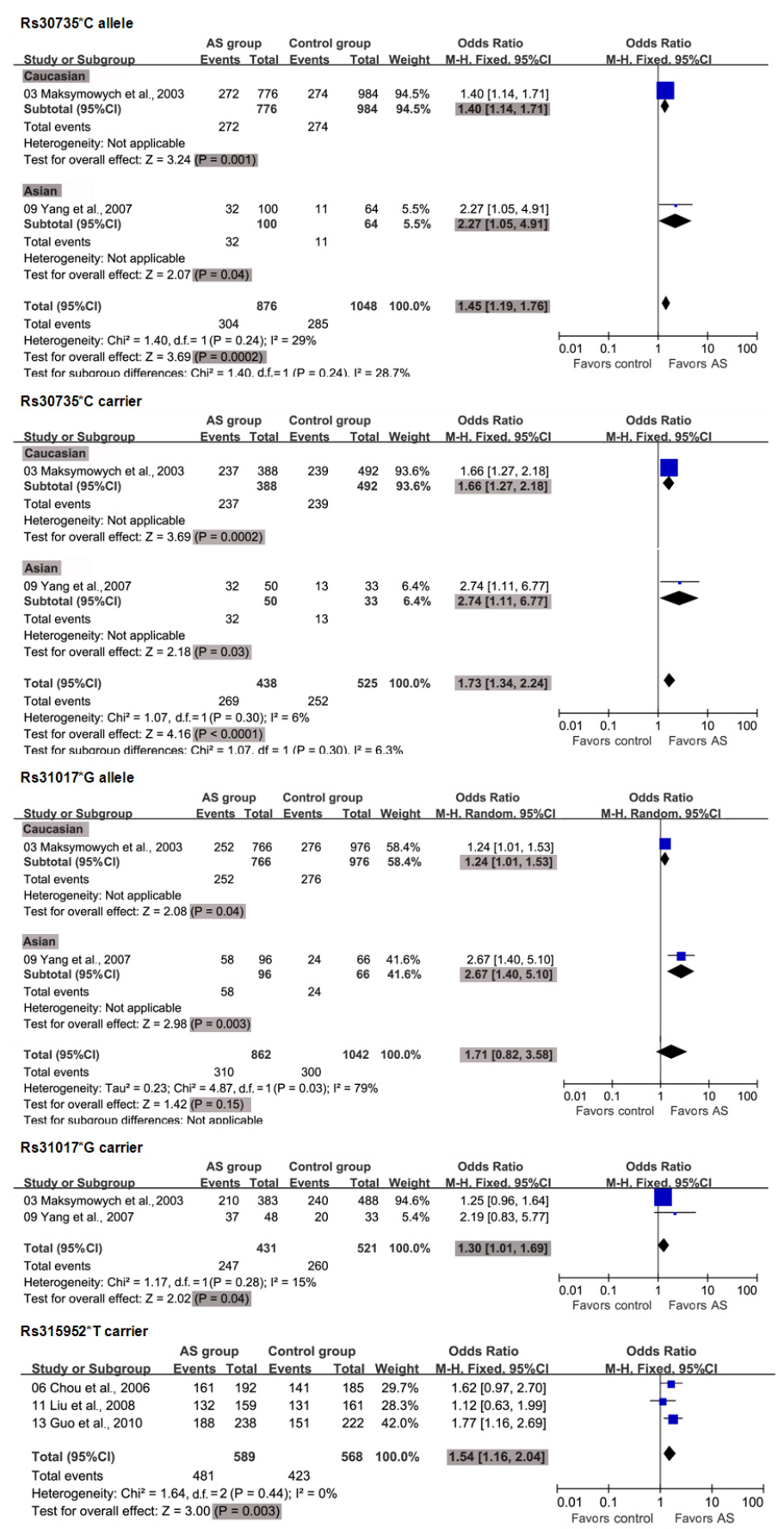

Figure 2. Association of rs $30735 * \mathrm{C}$ allele, rs $30735^{*} \mathrm{C}$ carrier, rs $31017 * \mathrm{G}$ allele, rs $31017 * \mathrm{G}$ carrier, and rs $315952 * \mathrm{~T}$ carrier with susceptibility to AS. The squares and horizontal lines correspond to the study-specific OR and $95 \%$ CI. The diamond represents the summary OR and 95\%CI. 


\section{Publication bias}

All Begger funnel plots appeared to be symmetrical (Figure 3). The Egger test also showed no statistical significance for all evaluations of publication bias (all $\mathrm{P}>0.05$ ). The findings of the Egger publication bias test are shown in Table 3.
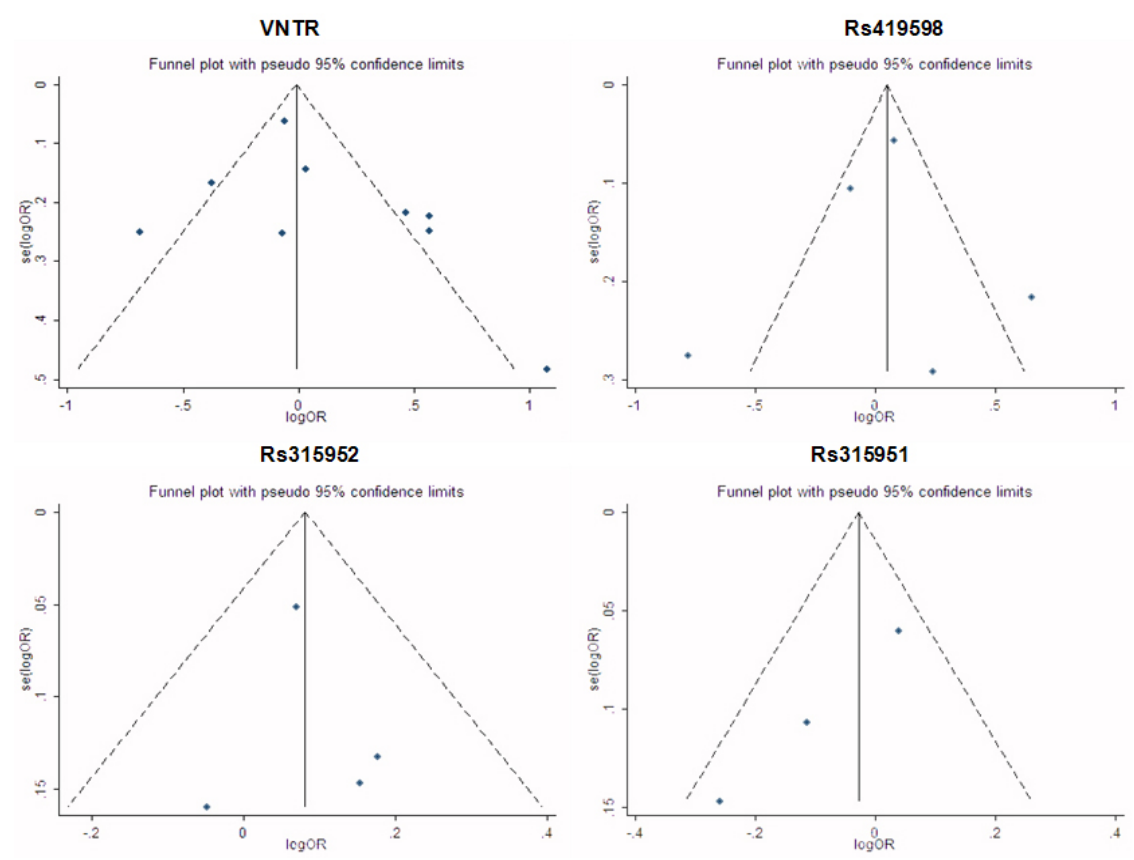

Figure 3. The Begger funnel plot of publication bias for the association between VNTR, rs419598, rs 315952 , rs315951, and susceptibility to AS.

Table 3. Evaluation of publication bias by the Egger linear regression test.

\begin{tabular}{lccrrr}
\hline SNP & Coefficient & SE & $t$ & P & $95 \%$ CI \\
\hline VNTR & 1.371 & 1.257 & 1.090 & 0.311 & $(-1.601,4.343)$ \\
rs419598 & -0.281 & 2.012 & -0.140 & 0.898 & $(-6.685,6.123)$ \\
rs315952 & 0.241 & 0.880 & 0.270 & 0.810 & $(-3.543,4.026)$ \\
rs315951 & -3.397 & 0.096 & -35.480 & 0.018 & $(-4.613,-2.180)$ \\
\hline
\end{tabular}

$\mathrm{SE}=$ standard error; $95 \% \mathrm{CI}=95 \%$ confidence interval. For other abbreviations, see legend to Table 1.

\section{DISCUSSION}

AS is a common, chronic, inflammatory arthritis, and autoimmune disease that mainly affects joints in the spine and the sacroiliac joint in the pelvis, causing eventual fusion of the spine (El Maghraoui, 2011). Its global prevalence ranges from 0 to $1.9 \%$, and is more prevalent in males (Feldtkeller et al., 2003; Baek et al., 2004). Although the exact cause of AS is unknown, we do know that genetic factors play a key role (Stewart and Ralston, 2000). The 
HLA-B27 genotype is expressed in about $90 \%$ of AS patients, meaning that there is a strong genetic association. However, only 5\% of individuals with the HLA-B27-positive genotype develop the disease (Reveille, 2006). Recently, a study conducted in Scotland found an association between the IL-1RN VNTR*2 allele and AS risk (McGarry et al., 2001). IL-1RN encodes the IL-1Ra protein, a member of the IL- 1 cytokine family. This protein inhibits IL- $1 \alpha$ and IL-1 $\beta$ activities and modulates a variety of IL-1-related immune and inflammatory responses (Perrier et al., 2006). Although many relevant studies have indicated an association between IL-1RN SNPs and increased risk of AS (Brown et al., 2000), the results are controversial.

In our meta-analysis, we found 3 SNPs in IL-1RN with strong evidence of association with AS risk after adjustment of multiple testing in the IL-1RN gene, including rs30735, rs 31017 , and $\mathrm{rs} 315952$. Our study showed that $\mathrm{rs} 30735^{*} \mathrm{C}$ allele/carrier, $\mathrm{rs} 31017^{*} \mathrm{G}$ carrier, and $\mathrm{rs} 315952 * \mathrm{~T}$ carrier have significant associations with AS risk after adjustment for multiple testing. The rs $315952 * \mathrm{~T}$ carrier was significantly associated with AS risk $(\mathrm{OR}=1.54)$ in 3 studies, but no association was found between the rs $315952 *$ T allele and AS risk. There was also no association between rs315951 and AS risk (all P > 0.05). However, Chou et al. (2006) reported substantially stronger haplotype associations with AS risk by combining rs 315952 and rs315951 using linkage disequilibrium statistics, because of under-representation of C homozygosity among AS cases. It is therefore likely that the association of these SNPs with disease reflects linkage disequilibrium with the primary disease locus, as implied by the association with specific inferred haplotypes. In addition, rs $30735^{*} \mathrm{C}$ allele/carrier and $\mathrm{rs} 31017^{*} \mathrm{G}$ carrier were associated with AS risk with 1.45, 1.73, and 1.30 OR based on 2 published studies (Lin et al., 2006; Maksymowych et al., 2006). Unfortunately, although a recent collaborative study found an association of AS with IL-1RN SNPs and their haplotypes, pooled analyses have not examined the relationship between $\mathrm{rs} 27810^{*} \mathrm{C}$ allele/carrier, rs $31017^{*} \mathrm{G}$ allele, rs $315951 * \mathrm{G}$ allele/carrier, rs $315952 * \mathrm{~T}$ allele, rs $419598^{*} \mathrm{C}$ allele/carrier, VNTR $* 2$ allele/carrier with AS risk. Some studies showed that ethnicity might influence AS susceptibility through variations in genetic background and environmental exposure, leading to various gene-gene and gene-environment interactions. In the subgroup analysis based on ethnicity, the $\operatorname{rs} 30735^{*} \mathrm{C}$ allele/carrier, and the $\mathrm{rs} 31017^{*} \mathrm{G}$ allele appear to be risk factors for AS in both Caucasians and Asians, while the rs $315952 * \mathrm{~T}$ carrier was associated with AS susceptibility only in an Asian population. Ethnicity-specific disease associations may arise from differences in genetic linkage disequilibrium structure across populations or due to other unknown environmental or genetic contributors. This influence may only involve susceptibility to and not severity of disease. Thus, meaningful studies in different ethnic backgrounds and in families of AS patients are needed to further establish or adjust this association.

Limitations in our meta-analysis should be addressed. First, because only published studies were included in the meta-analysis, the relevant research articles are few and the sample size was not large. Second, although the funnel plot and the Egger test showed no publication bias, selection bias could have occurred because only studies published in English or Chinese were included. Third, we could remove some variability by performing ethnicityspecific analysis, but there were other sources of heterogeneity, and the genotype distribution deviated from HWE in some studies. In addition, analyses were not conducted for all variants ever evaluated in the context of AS susceptibility. Most important, our meta-analysis was based on unadjusted OR estimates because not all publications presented adjusted ORs and when they did, the ORs were not adjusted by the same potential confounders, such as ethnicity, 
gender, geographic distribution, etc. Given these results, additional investigation in these areas is needed, and our conclusions should be interpreted cautiously.

In conclusion, this meta-analysis of 13 case-control studies demonstrated that 3 IL$1 \mathrm{RN}$ polymorphisms are associated with susceptibility to AS. The rs $30735^{*} \mathrm{C}$ allele/carrier and the rs $31017 * \mathrm{G}$ allele are potential risk factors for AS in Caucasians and Asians, while only the rs $315952 * \mathrm{~T}$ carrier was associated with AS susceptibility in the Asian population. Since only a few studies are available in this field and evidence remains limited, we emphasize the necessity to conduct large studies with adequate methodological quality and proper control of confounding factors to obtain valid results.

\section{REFERENCES}

Agrawal S, Srivastava R, Sharma B, Pandya S, et al. (2008). IL1RN*2 allele of IL-1receptor antagonist VNTR polymorphism is associated with susceptibility to ankylosing [corrected] spondylitis in Indian patients. Clin. Rheumatol. 27: 573-576.

Baek HJ, Shin KC, Lee YJ, Kang SW, et al. (2004). Clinical features of adult-onset ankylosing spondylitis in Korean patients: patients with peripheral joint disease (PJD) have less severe spinal disease course than those without PJD. Rheumatology 43: 1526-1531.

Baraliakos X, Listing J, Rudwaleit M, Sieper J, et al. (2008). The relationship between inflammation and new bone formation in patients with ankylosing spondylitis. Arthritis Res. Ther. 10: R104.

Braun J and Sieper J (2007). Ankylosing spondylitis. Lancet 369: 1379-1390.

Brown MA, Laval SH, Brophy S and Calin A (2000). Recurrence risk modelling of the genetic susceptibility to ankylosing spondylitis. Ann. Rheum. Dis. 59: 883-886.

Chou CT, Timms AE, Wei JC, Tsai WC, et al. (2006). Replication of association of IL1 gene complex members with ankylosing spondylitis in Taiwanese Chinese. Ann. Rheum. Dis. 65: 1106-1109.

Duan Z, Pan F, Zeng Z, Zhang T, et al. (2012). Interleukin-23 receptor genetic polymorphisms and ankylosing spondylitis susceptibility: a meta-analysis. Rheumatol. Int. 32: 1209-1214.

El Maghraoui A (2011). Extra-articular manifestations of ankylosing spondylitis: prevalence, characteristics and therapeutic implications. Eur. J. Intern. Med. 22: 554-560.

Feldtkeller E, Khan MA, van der Heijde D, van der Linden S, et al. (2003). Age at disease onset and diagnosis delay in HLA-B27 negative vs. positive patients with ankylosing spondylitis. Rheumatol. Int. 23: 61-66.

Guo ZS, Li C, Lin ZM, Huang JX, et al. (2010). Association of IL-1 gene complex members with ankylosing spondylitis in Chinese Han population. Int. J. Immunogenet. 37: 33-37.

Higgins JP and Thompson SG (2002). Quantifying heterogeneity in a meta-analysis. Stat. Med. 21: 1539-1558.

Kim TH, Stone MA, Rahman P, Yoo DH, et al. (2005). Interleukin 1 and nuclear factor-kappaB polymorphisms in ankylosing spondylitis in Canada and Korea. J. Rheumatol. 32: 1907-1910.

Laval SH, Timms A, Edwards S, Bradbury L, et al. (2001). Whole-genome screening in ankylosing spondylitis: evidence of non-MHC genetic-susceptibility loci. Am. J. Hum. Genet. 68: 918-926.

Lin L, Chen WG and Hu FP (2006). Interleukin-1R and interleukin-1 receptor antagonist gene polymorphisms in Hu'nan Han nationoality ankylosing spondylitis patient. Clin. J. Rheumatol. 10: 726-728.

Liu H, Kong XD, Cai Q, Lu HQ, et al. (2008). The effect of single nucleotide polymorphism in interleukin-1 gene on the susceptibility of ankylosing spondylitis in Chinese Han population. Chin. J. Rheumatol. 12: 304-308.

Maksymowych WP, Reeve JP, Reveille JD, Akey JM, et al. (2003). High-throughput single-nucleotide polymorphism analysis of the IL1RN locus in patients with ankylosing spondylitis by matrix-assisted laser desorption ionizationtime-of-flight mass spectrometry. Arthritis Rheumatol. 48: 2011-2018.

Maksymowych WP, Rahman P, Reeve JP, Gladman DD, et al. (2006). Association of the IL1 gene cluster with susceptibility to ankylosing spondylitis: an analysis of three Canadian populations. Arthritis Rheumatol. 54: 974-985.

McGarry F, Neilly J, Anderson N, Sturrock R, et al. (2001). A polymorphism within the interleukin 1 receptor antagonist (IL-1Ra) gene is associated with ankylosing spondylitis. Rheumatology 40: 1359-1364.

Peloso PM, Gammaitoni A, Smugar SS, Wang H, et al. (2011). Longitudinal numbers-needed-to-treat (NNT) for achieving various levels of analgesic response and improvement with etoricoxib, naproxen, and placebo in ankylosing spondylitis. BMC Musculoskelet. Disord. 12: 165.

Perrier S, Darakhshan F and Hajduch E (2006). IL-1 receptor antagonist in metabolic diseases: Dr Jekyll or Mr Hyde? 
FEBS Lett. 580: 6289-6294.

Peters JL, Sutton AJ, Jones DR, Abrams KR, et al. (2006). Comparison of two methods to detect publication bias in metaanalysis. JAMA 295: 676-680.

Reveille JD (2006). Major histocompatibility genes and ankylosing spondylitis. Best. Pract. Res. Clin. Rheumatol. 20: 601-609.

Reveille JD, Sims AM, Danoy P, Evans DM, et al. (2010). Genome-wide association study of ankylosing spondylitis identifies non-MHC susceptibility loci. Nat. Genet. 42: 123-127.

Sims AM, Timms AE, Bruges-Armas J, Burgos-Vargas R, et al. (2008). Prospective meta-analysis of interleukin 1 gene complex polymorphisms confirms associations with ankylosing spondylitis. Ann. Rheum. Dis. 67: 1305-1309.

Stewart TL and Ralston SH (2000). Role of genetic factors in the pathogenesis of osteoporosis. J. Endocrinol. 166: 235-245.

Timms AE, Crane AM, Sims AM, Cordell HJ, et al. (2004). The interleukin 1 gene cluster contains a major susceptibility locus for ankylosing spondylitis. Am. J. Hum. Genet. 75: 587-595.

van der Paardt M, Crusius JB, Garcia-Gonzalez MA, Baudoin P, et al. (2002). Interleukin-1beta and interleukin-1 receptor antagonist gene polymorphisms in ankylosing spondylitis. Rheumatology 41: 1419-1423.

Vandenbroucke JP, von Elm E, Altman DG, Gotzsche PC, et al. (2007). Strengthening the reporting of observational studies in epidemiology (STROBE): explanation and elaboration. Epidemiology 18: 805-835.

Yang Y, Su ZW, Ma WS, Cai AJ, et al. (2007). Single nucleotide polymorphism of IL-1RN and TNF- $\alpha$ in ankylosing spondylitis. J. Trop. Med. 7: 948-951.

Zhang L, Liu JL, Zhang YJ and Wang H (2011). Association between HLA-B*27 polymorphisms and ankylosing spondylitis in Han populations: a meta-analysis. Clin. Exp. Rheumatol. 29: 285-292.

Zintzaras E and Ioannidis JP (2005). Heterogeneity testing in meta-analysis of genome searches. Genet. Epidemiol. 28: 123-137. 